\title{
The interaction of northern wind flow with the complex topography of Crete Island - Part 1: Observational study
}

\author{
I. Koletsis ${ }^{1,2}$, K. Lagouvardos ${ }^{2}$, V. Kotroni ${ }^{2}$, and A. Bartzokas ${ }^{1}$ \\ ${ }^{1}$ University of Ioannina-Laboratory of Meteorology, Department of Physics, Ioannina, Greece \\ ${ }^{2}$ National Observatory of Athens, Institute of Environmental Research, Athens, Greece
}

Received: 19 March 2009 - Revised: 27 October 2009 - Accepted: 29 October 2009 - Published: 11 November 2009

\begin{abstract}
The island of Crete with its mountain ranges is an excellent example of a major isolated topographic feature, which significantly modifies the regional airflow as well as the pressure and temperature fields. During summer, when northerly winds are blowing over the Aegean Sea (a large number of which are characterized as Etesians), the highly complex topography of Crete plays an important role in the modification of this northern wind flow. The main objective of this study is to determine the role of the topography of Crete Island during this wind flow on the strong downslope winds at the southern parts of the island as well as on the development of a gap flow between the two highest mountains of the island (Lefka Ori and Idi). For that purpose, observational data from four meteorological stations located along the aforementioned gap are used along with QuikSCAT satellite data. The observational analysis shows that the interaction of the northern wind flow with the mountains of Crete Island produces an upstream deceleration, a leftward deflection of the air as this approaches the mountains and an intensification of the winds at the southern coasts accompanied with a temperature increase. Furthermore, the maximum of the gap flow is observed at the exit region of the gap.
\end{abstract}

\section{Introduction}

During the summer months strong winds from northern directions, named Etesians, blow over the Aegean Sea. They are mainly northeasterly in northern Aegean, northerly in central and southern Aegean, while they become northwesterly in southeastern Aegean. Etesian winds are usually dry and relatively cool, as they are bringing relatively cool continental air from the region of southern Russia and the Caspian

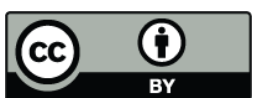

Correspondence to: I. Koletsis

(koletsis@meteo.noa.gr)
Sea, contributing to the decrease of surface temperature and the moderation of summer heat and discomfort (Meteorological Office, 1962). The wind speed associated with the Etesians might reach gale force over off-shore areas, creating problems to maritime transport within the Aegean Sea during the high touristic season. Moreover, Etesian winds play an important role in the expansion of forest fires in the southern part of continental Greece and in the islands of the Aegean Sea.

Etesian winds are the combined result of the Persian Gulf trough (its western edge) and the extension of the subtropical high pressure system over the Eastern Mediterranean (Meteorological Office, 1962; Metaxas, 1977; Prezerakos, 1975; Bitan and Saaroni, 1992; Ziv et al., 2004). Additionally, the Etesian flow is related to the passage of cold fronts over the Balkans and the associated cold-air circulation behind them (Kotroni et al., 2001). The direction of the Etesian flow is affected by the complex topographic features of the area, which include high mountains in continental Greece, southern Balkans and Turkey, and a large number of islands of various sizes within the Aegean Sea (Fig. 1a). Brody and Nestor (1985) pointed out that these topographical features can create channeling between the islands and the mainland, as well as corner and obstacle effects over the mountain barriers. Moreover, mountains oriented perpendicular to the Etesian direction (e.g. the mountains of Crete, Fig. 1b) can significantly decelerate the wind flow on their upwind side (Kotroni et al., 2001).

The synoptic conditions that lead to the onset of Etesian winds have been studied analytically during the past, as mentioned before. The analysis however of the Etesian wind flow and its interaction with the complex topographic features of the Aegean Sea have received little attention. Kotroni et al. (2001) presented an observational and numerical study of the interaction of the wind flow under an Etesian wind regime with the island of Crete. The results of the study revealed a deceleration zone upstream of the island up to

Published by Copernicus Publications on behalf of the European Geosciences Union. 
almost $120 \mathrm{~km}$, a leftward deflection of the wind flow around the island, as well as formation of wakes in the lee of the island.

In the literature, there are many observational studies that analyzed the interaction of the wind flow with complex topographic features, including the wind flow modification in mountainous gaps. Overland (1984) showed that the momentum balances within gaps and their exit regions are highly dependent on the length and width scales of the gap. Smith et al. (1997) used satellite images as well as boat and lowlevel aircraft surveys to investigate the wake of St. Vincent in the southeastern Caribbean. Pan and Smith (1999) examined the terrain-induced gap winds and wakes in the atmosphere using surface wind data from synthetic aperture radar (SAR) in the Unimak Island. Colle and Mass (2000) used Doppler winds and flight-level data from the NOAA P-3 aircraft to illustrate some of the complex three-dimensional structures associated with easterly gap flow through the strait of Juan de Fuca and Sharp and Mass (2004) used ground stations across the Columbia gorge gap to estimate the local climatological wind regime.

The study of Etesian wind interaction with the topography of Crete Island by Kotroni et al. (2001) suffered by the absence of available observations over the island. In the frame of the present study four ground meteorological stations were deployed along the gap between the two major mountains Lefka Ori and Idi on the island of Crete with the aim to study the wind flow modification along the gap under northerly wind regime. The observational analysis was supplemented with satellite high resolution data from QuikSCAT, in order to study the wind flow around the island of Crete, as well as the wind conditions over the maritime area upstream of the gap entrance and downstream of the gap exit during summer 2007. Additionally, sounding data from Heraclion Airport have been used (Fig. 1b) for the study of the upstream atmospheric structure.

The structure of the paper is the following: Sect. 2 is devoted to the description of the observational data set used in the study. Section 3 presents the results of the statistical analyses, of the observational data during the days of northern wind flow of summer 2007 together with aspects of relevant theoretical results and estimations. A case study of a strong Etesian episode (24 August 2007) with the behavior of the wind flow along the gap as well as the general modification of the airflow due to the topographic elements of Crete Island and the upstream vertical atmospheric structure is carried out in Sect. 4, while in Sect. 5 conclusions are drawn.

\section{Observational data description}

The island of Crete is located in the southern Aegean Sea and has a long and narrow shape, with a west-east axis oriented perpendicular to the prevailing northern wind flow (latitude approximately $34.9^{\circ} \mathrm{N}-35.7^{\circ} \mathrm{N}$, longitude approximately
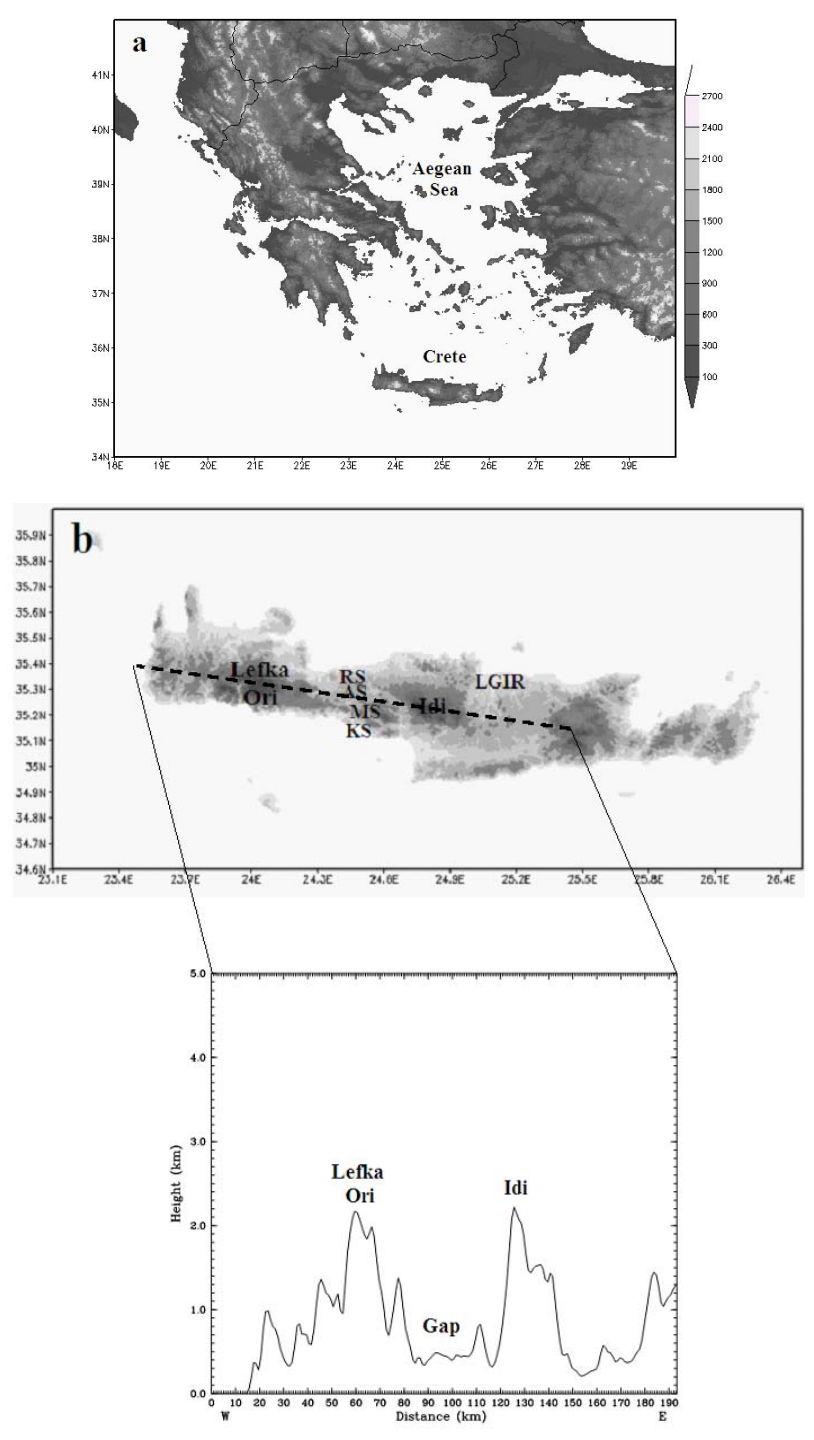

Fig. 1. Maps of (a) Greece, (b) Crete Island showing the locations of the mountains (Lefka Ori and Idi) and of the ground stations at Rethymno (RS), Armeni (AS), Mourne (MS) and Kerame (KS), as well as the Heraclion Airport (LGIR). The black dashed rectangles represent the maritime areas upstream and downstream of the gap entrance and gap exit, respectively. Also, the island profile as seen from the south the locations of the mountains and the gap are marked.

$23.4^{\circ} \mathrm{E}-26.4^{\circ} \mathrm{E}$ ) (Fig. 1a). The Cretan topography is characterized by high mountains on the central and western part of the island where the peaks reach $2400 \mathrm{~m}$, while mountains with lower crests are found on the eastern part. In the mainland of the island, numerous gaps are found between the mountains. One of the more important gaps is located between the two highest mountain, Lefka Ori $(2453 \mathrm{~m})$ and Idi $(2456 \mathrm{~m})$ (Fig. 1b). It has a north-south length $\sim 25 \mathrm{~km}$, and a width of 30-40 km and its topography consists of many hills and smaller mountains that range from $100-600 \mathrm{~m}$ in elevation. 
During the summer 2007 (from July to September) four meteorological stations have been deployed along the gap between the two highest mountains of Crete (Lefka Ori and Idi), namely at Rethymno, Armeni, Mourne and Kerame (Fig. 1b). A meteorological station contains: an anemometer vane, a three-cup anemometer, a rain gauge, temperature and humidity sensors protected by a fan-aspirated shield, as well as a barometer. In each of the four locations temperature and humidity were measured at 2 and $5 \mathrm{~m}$, while wind speed and direction were recorded at both 5 and $10 \mathrm{~m}$. The stations' data sampling is $2.5 \mathrm{~s}$, while for the wind speed analysis, data averaged over five minutes were used. Moreover, the observed maximum wind speed during the five minutes period is considered as wind gust. The stations were located over different terrain, both coastal and inland, as well as in relatively flat and mountainous terrain (Table 1). Rethymno Station (RS) is located in the northern part of the island, at the entrance of the gap and it is ideal for the analysis of the initial flow before its interaction with the gap. Kerame Station (KS) was chosen because it is located at the exit of the gap thereby the weather conditions are strongly correlated with the gap influence. Additionally, the two inland stations at Armeni (AS) and Mourne (MS), located inside the gap, can be considered as representative for the study of the modification of the initial flow along the gap. It should be noticed that all the stations were located in rural locations in order to avoid erroneous measurements due to urban effects.

A large number of the wind data used in this study were obtained from the SeaWinds scatterometer onboard the National Atmospheric and Space Administration QuikSCAT satellite (Lungu et al., 2006). The SeaWinds scatterometer is a Ku-band scatterometer that estimates the ocean surface vector by measuring the backscatter due to centimeterscale capillary waves on the ocean surface (Brennan et al., 2007). QuikSCAT nominally provides wind retrievals with a horizontal resolution of $25 \mathrm{~km}$, and since 2003 Near Real Time (NRT) $12.5 \mathrm{~km}$ retrievals are also available. In this study data with spatial resolution of $12.5 \mathrm{~km}$ (Level 2B) were used. According to the sensor specifications, the QuikSCAT winds have an accuracy of $\pm 0.2 \mathrm{~m} \mathrm{~s}^{-1}$ for the wind speed and $\pm 20^{\circ}$ for the direction (in the wind speed range of 3$20 \mathrm{~m} \mathrm{~s}^{-1}$ ). Retrieved winds are referenced to a $10 \mathrm{~m}$ height above sea level, at neutral air-sea stability conditions. The SeaWinds instrument's measurement swath extends $900 \mathrm{~km}$ on either side of the satellite nadir track providing the best temporal sampling of the Aegean Sea. QuikSCAT samples the Aegean Sea twice a day, in the early morning and afternoon hours. Moreover, the confidence in the accuracy of QuikSCAT retrievals is high for the summer northerly wind flow (including Etesian days) since these periods are rainfree (rain contamination is a source of error in QuikSCAT retrievals). Additionally during summer, the northerly wind flow presents moderate to strong intensities and thus the corresponding QuikSCAT wind observations are expected to be of very good quality.
Table 1. General characteristics of the stations.

\begin{tabular}{|c|c|c|c|c|}
\hline Station & Latitude & Longitude & $\begin{array}{l}\text { Height } \\
\text { level } \\
\text { (m) }\end{array}$ & Location \\
\hline Rethymno & $35^{\circ} 22^{\prime} 04^{\prime \prime} \mathrm{N}$ & $24^{\circ} 26^{\prime} 40^{\prime \prime} \mathrm{E}$ & 25 & coastal \\
\hline Armeni & $35^{\circ} 17^{\prime} 50^{\prime \prime} \mathrm{N}$ & $24^{\circ} 27^{\prime} 26^{\prime \prime} \mathrm{E}$ & 359 & $\begin{array}{l}\text { inland and } \\
\text { flat }\end{array}$ \\
\hline Mourne & $35^{\circ} 12^{\prime} 34^{\prime \prime} \mathrm{N}$ & $24^{\circ} 31^{\prime} 21^{\prime \prime} \mathrm{E}$ & 509 & $\begin{array}{l}\text { inland and } \\
\text { mountainous }\end{array}$ \\
\hline Kerame & $35^{\circ} 08^{\prime} 53^{\prime \prime} \mathrm{N}$ & $24^{\circ} 30^{\prime} 10^{\prime \prime} \mathrm{E}$ & 10 & coastal \\
\hline
\end{tabular}

\section{Observational data process}

Stations data are used in this study to analyze the weather conditions within and along the mountain gap in centralwestern Crete. During the 92-days experiment period (from July to September 2007), there were 48 days where the wind speed was at least $5 \mathrm{~m} \mathrm{~s}^{-1}$ at $10 \mathrm{~m}$ from northern directions (west-north-western to east-north-eastern directions) at the KS at noon and afternoon hours (12:00 to 19:00 local summer time $=09: 00$ to 16:00 UTC). These days were characterized as northern wind flow days (NWFD, hereafter). The threshold of $5 \mathrm{~m} \mathrm{~s}^{-1}$ was chosen arbitrarily, in order to avoid light wind intensities resulted from local effects (e.g. sea/land breezes). The above-mentioned time period was selected because many studies which have been devoted to strong northerly flow over Aegean have identified the noontime intensification of the Etesian flow (Metaxas and Bartzokas, 1994). The Etesian days are included in NWFD, when the appropriate synoptic development is established. The high percentage of NWFD ( $\sim 52 \%, 48 / 92$ days), point out that the northern airflow over the Aegean Sea is the prevailing wind regime over the Aegean during the summer months.

\subsection{Process of stations' wind data}

The distribution of wind direction during the 48 NWFD for all ground stations is presented in Fig. 2a. As expected, the wind from northern sector (northwest to north-northeast) was the prevailing wind direction for all locations. For RS (the northern most station) the northwestern direction dominates during the northern wind flow (24\% of data records), while at AS the prevailing direction was from north-northwest $(\sim 47 \%)$. North winds prevail at locations near the gap exit during the NWFD, occurring on about $56 \%$ of data records at $\mathrm{KS}$ as well as $\sim 45 \%$ for MS. As shown in Fig. 2a, a veering of the prevailing wind direction airflow is observed along the gap as a result of local scale topographic channeling effects. It is worth noting that RS presents a significant percentage of southerly winds $(\sim 16 \%)$ during the NWFD. According to the statistical analysis, these southern winds are observed during nighttime and early morning hours (23:00 to 07:00 
a

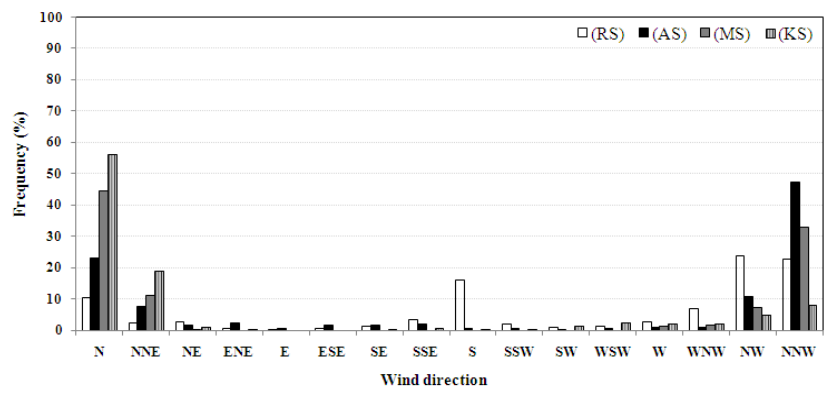

b

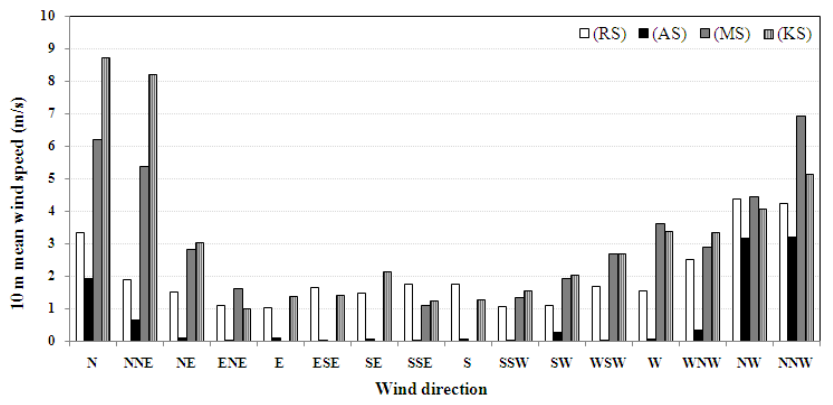

Fig. 2a, b. Bar diagrams for all stations of (a) frequency (\%) of occurrence as a function of wind direction, (b) $10 \mathrm{~m}$ wind speed distribution per wind direction for the period of NWFD.

local summer time, LST). Moreover, these winds are light as Fig. $2 \mathrm{~b}$ shows. The wind direction as well as the wind speed in RS, strongly suggests the development of a land breeze during nighttime in this area. The higher wind speeds blow from northern direction at the near gap exit stations, with a mean speed of $\sim 9 \mathrm{~m} \mathrm{~s}^{-1}$ and $7 \mathrm{~m} \mathrm{~s}^{-1}$ for KS and MS, respectively (Fig. 2b).

In order to examine the relationship between the location of each station with the intensity of the northern flow, a classification of the wind intensity was attempted. For this purpose, the available 5-min wind data records were rounded to the nearest integer. The wind data were classified in 6 categories: the calm class with zero mean wind speed, the light class $\left(1-3 \mathrm{~m} \mathrm{~s}^{-1}\right)$, the near moderate class $\left(4-6 \mathrm{~m} \mathrm{~s}^{-1}\right)$, the moderate class $\left(7-9 \mathrm{~m} \mathrm{~s}^{-1}\right)$, the strong class $\left(10-12 \mathrm{~m} \mathrm{~s}^{-1}\right)$ and the near gale class with mean wind speeds greater than $12 \mathrm{~m} \mathrm{~s}^{-1}$. The frequency of occurrence of these classes during the NWFD is shown in Fig. 2c. At RS the maximum frequency of occurrence is observed at the light class category, followed by the near moderate, with the very low percentages for higher wind classes. At AS the first three classes present the higher percentages, followed by an abrupt decrease of occurrence at the moderate class. At MS the maximum frequency of occurrence is observed at the near moderate class, followed by the moderate class. Finally, at KS the maximum frequency of occurrence is observed at the moderate class, followed by the strong and near gale class. It is noticeable that strong as well as near gale wind classes are presented in c

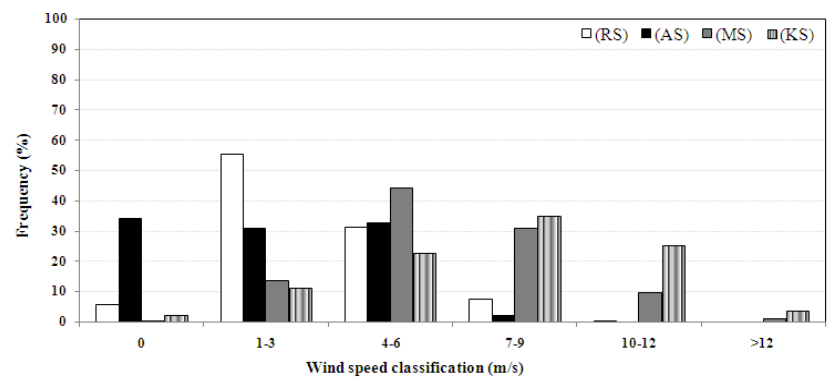

d

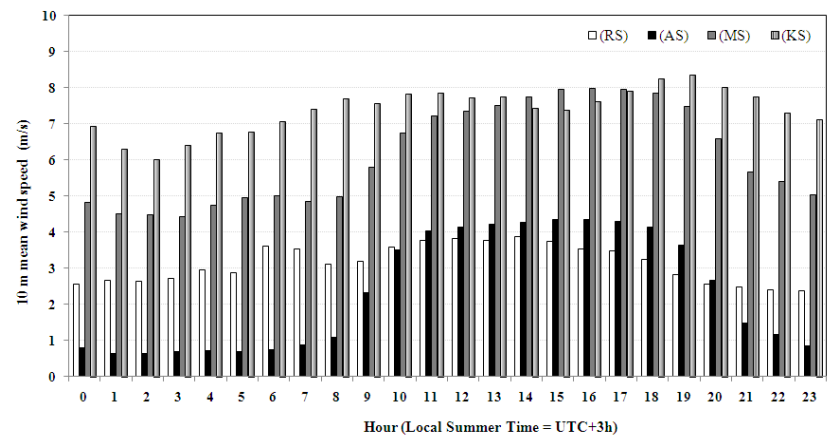

Fig. 2c, d. Bar diagrams for all stations of (c) distribution of frequency occurrence as a function of wind speed classification, and (d) hourly distribution of $10 \mathrm{~m}$ wind speed $(\mathrm{m} / \mathrm{s})$ classification for the period of NWFD.

the KS and MS wind data. These results are consistent with the aspect that stronger gap winds usually occur at the gap exit region contrary to the Venturi effect.

The Venturi effect is a well supported explanation for the strong winds observed in gaps. This effect is based on mass conservation principles that state that the strongest winds should be observed at the narrowest part of the gap (Reed, 1931). However, in many studies worldwide the strongest winds have been observed in the exit areas of the gaps such as in the strait of Juan de Fuca (Overland and Walter, 1981; Colle and Mass, 2000) and in Columbia gorge gap (Sharp and Mass, 2002). This fact indicates that the main cause of the strong winds seen in gaps is not the Venturi effect. The most important factor that plays a significant role in these gap wind events is the pressure gradient. However, additional wind maxima could be present within a gap due to Venturi or other hydraulic effects (Sharp and Mass, 2002).

In order to investigate the diurnal variability of the wind speed, the hourly distribution at Local Summer Time $(\mathrm{LST}=\mathrm{UTC}+3 \mathrm{~h})$ of wind data along the gap was examined (Fig. 2d). According to the hourly distribution, the higher wind speeds for all stations are observed during noon and early afternoon hours. The main characteristics of this distribution were the higher wind speeds which are recorded at KS followed by MS, and the high frequency of calm 
conditions at AS (as shown also in Fig. 2c), during the late night and early morning. It is noticeable that the inland stations (AS, MS) present the higher intra-daily wind speed difference $\left(\sim 4 \mathrm{~m} \mathrm{~s}^{-1}\right)$ in contrary to the coastal stations (RS, KS) $\left(\sim 2 \mathrm{~m} \mathrm{~s}^{-1}\right)$.

The strongest winds observed under the northerly wind regime are related to fluctuations in the wind speed at periods as short as a few seconds. These fluctuations, known as wind gusts, can cause damages in construction and disruption of maritime transport, as their strength may exceed twice the mean wind speed (Durran, 1990). During the analyzed period (NWFD) the maximum wind gusts were recorded in KS and MS, with $25 \mathrm{~m} \mathrm{~s}^{-1}$ and $22 \mathrm{~m} \mathrm{~s}^{-1}$ respectively. The relative strength of the gust is described by the gust factor, which is calculated from the ratio of peak gust to the sustained speed. The sustained wind speed is the mean wind speed over a 5-minute averaging period while the peak gust is the highest value recorded during this time interval at $10 \mathrm{~m}$ height. In this study the gust analysis has been applied for July and August 2007 wind data, only when gust records at $10 \mathrm{~m}$ were available. Gust factors are calculated for mean wind speeds greater than $5 \mathrm{~m} \mathrm{~s}^{-1}$.

The lower values of mean gust factor were calculated at RS (1.33) and MS (1.44), while the higher values were calculated at KS (1.62) followed by the AS (1.58). Figure 3 shows a boxplot of the gust factor as a function of wind speed for KS. The graph shows a normal decrease of the gust factor for increasing wind speed. At high wind speeds, the decrease is slightly abrupt, but that is possibly related to the limited number of data. According to the gust factor analysis, strong gusts can be produced downstream of the high mountains and at the gap exit, which embedded between the mountains. The interaction of the air flow with the topography of Crete Island seems to accentuate the gust-producing effect of topography due to the local turbulence development. Additionally, the intra-daily variation of the observed mean hourly averaged wind gust factor at KS was of order of $10 \%$ (not shown). Note that at KS the intra-daily variation of the mean wind speed was also low (Fig. 2d).

\subsection{Pressure gradient and wind speed correlation}

The pressure gradient between the entrance and the exit of a gap is commonly used by many scientists to examine the strength of a gap flow (Overland and Walter, 1981; Colle and Mass, 2000; Sharp and Mass, 2004). In order to examine the evident correlation between the wind speed at KS and the pressure difference from both gap sides, the pressure and wind data from RS (gap entrance) and KS (gap exit) were used.

As it was discussed earlier in Fig. 2b, the stronger winds at KS blow from northern direction (NW to NNE). For this reason, pressure and wind data from RS and KS were sorted by the wind direction at KS and only the northwestern to northnortheastern data were analyzed. Figure 4 illustrates a strong

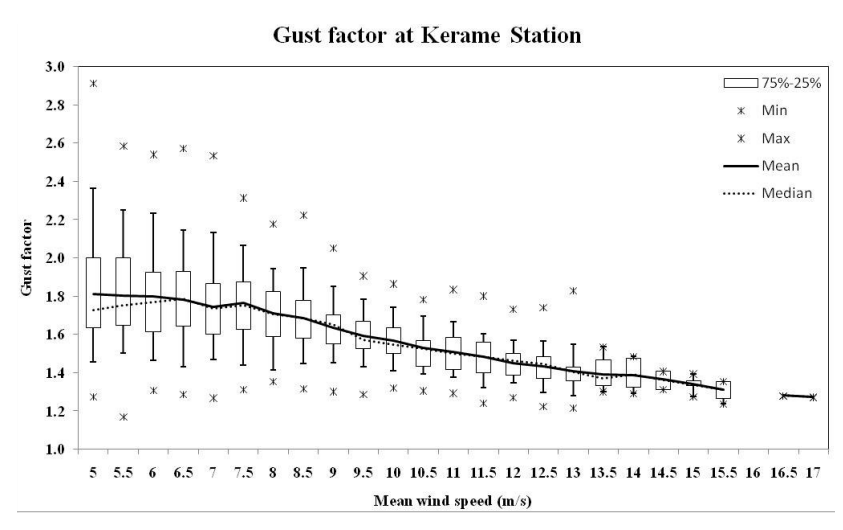

Fig. 3. A boxplot (also known as a box-and-whisker diagram) is a convenient way to graphically depict the groups of the numerical data. The upper edge of the box indicates the 75th percentile of the data set, and the lower edge indicates the 25 th percentile. The ends of the vertical lines indicate the 5th and 95th percentile of data values, while the two asterisks represent the maximum and the minimum value, respectively. Also, lines depict the mean value as well as the median $(50 \%)$ of the data. Wind speed data greater or equal to $5 \mathrm{~m} \mathrm{~s}^{-1}$ from KS throughout the NWFD were used.

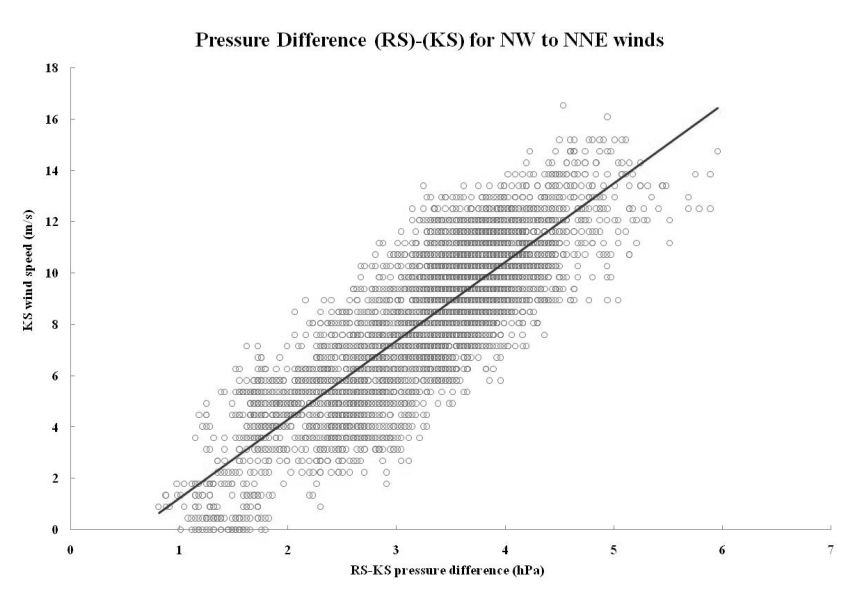

Fig. 4. Scatterplot of pressure gradient between RS and KS stations with the wind speed for northwestern to north-northeastern wind data records at KS for NWFD.

relationship of the pressure gradient between RS and KS with the wind speed at KS. The high value of the coefficient of determination (the square of the correlation coefficient in linear regression $)\left(R^{2}=0.70\right)$ implies that the pressure gradient between the entrance and gap exit regions is a fine indicator for the wind speed at KS during the periods of northern flow over the Aegean Sea. In order to assess the statistical significance of the coefficient of determination, $R^{2}$, we calculated the $T$ statistic that follows a Student distribution with $n-2$ degrees of freedom (Devore, 1991):

$T=\frac{R \sqrt{n-2}}{\sqrt{1-R^{2}}}$ 
The calculated $T$-statistic value was 108.20 with a corresponding, one-tailed, true level of significance equal to 0 , indicating that the null hypothesis of $R^{2}=0$ cannot be accepted.

A possible simple explanation for the relationship of windward/leeward pressure gradient with the strong gap winds is based on the interaction of the maritime undisturbed air from the Aegean Sea with the complex topography of Crete Island. When the subsiding air on the lee side of the high Cretan mountains warms adiabatically, then a decrease of sea level pressure occurs on the lee side. On the windward side of the barrier the relatively cool maritime air can be "dammed up" and deepen as it is blocked by the terrain, producing a windward pressure ridge. Thus, both lee "troughing" and windward "ridging" can increase the across-barrier pressure gradient and consequently strengthen the wind near the gap exit.

\subsection{Temperature and humidity process}

The wind flow during a northerly regime on Crete Island is also responsible for the modification of temperature and humidity fields along the gap. The relationship between wind direction and temperature - relative humidity fields between the gap entrance and exit, was examined using the data from RS and KS, during the NWFD. In order to investigate the clear wind effect on humidity field, only daily data from 08:00-20:00 LST were analyzed, leaving out the higher nighttime humidity measurements. The temperaturehumidity fields' analyses (not shown) reveal that the mean maximum temperature/humidity is higher/lower in KS, particularly when the wind is from northern directions (northwest to northeast). The dry and warm air that is observed in KS is result of the downslope flow. Moreover, lower/higher maximum temperature/humidity in $\mathrm{KS}$ is observed when the wind is from southern directions. This is because southerly flow advects wet and relatively cool maritime air to inland areas of the island. On the other hand, there is not any significant variation of relative humidity in RS, while the mean maximum temperatures are lower than KS.

\subsection{QuikSCAT's data process}

In order to study the wind conditions in the maritime area upstream of the gap entrance as well as at the maritime area downstream of the gap exit QuikSCAT data, which contained in the two rectangles that are illustrated at Fig. 1b throughout the NWFD, were selected for statistical analysis. Figure 5 presents the frequency of occurrence of the wind direction at the maritime area upstream and downstream of the gap during the NWFD. At the maritime area upstream of the gap entrance, the winds from the northern sector (NNW to NNE) were observed more frequently. It should be noted also, that the satellite wind data did not record any southerly flow at the gap entrance maritime area contrary to the significant frequency at the location of the gap entrance (RS), which have

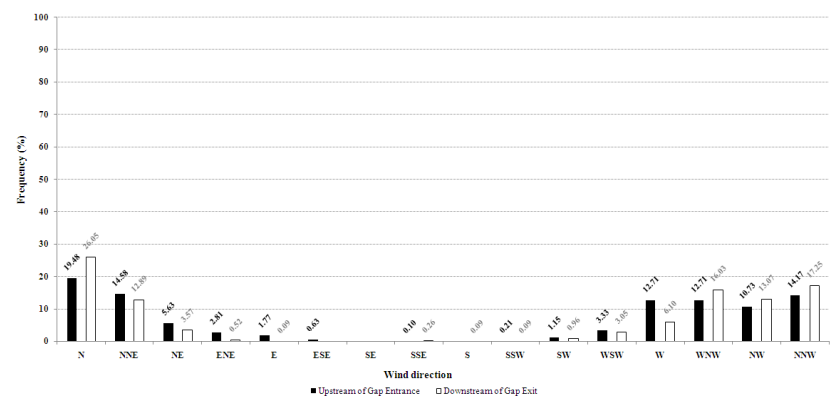

Fig. 5. Bar diagrams for the QuikSCAT data at the areas denoted with the two rectangles at Fig. 1b. The bar diagrams depicts the frequency $(\%)$ of occurrence as a function of wind direction for the maritime areas upstream of the gap entrance and downstream of the gap exit throughout the NWFD.

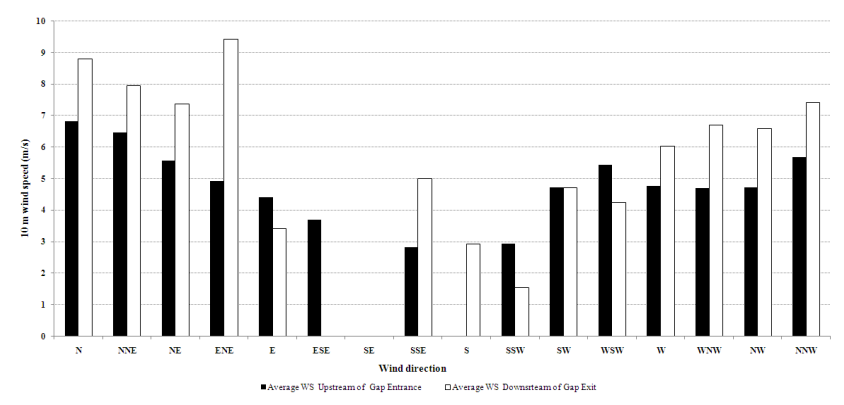

Fig. 6. As in Fig. 5, but for the $10 \mathrm{~m}$ wind speed distribution per wind direction at the maritime areas upstream of the gap entrance and downstream of the gap exit throughout the NWFD.

been indicated by ground stations measurements (Fig. 2a); since QuikSCAT data are not reported close to the coastline, where the land breeze is more evident. For the maritime area downstream of the gap exit in accordance with the wind direction distribution for KS, the prevailing wind sector was the northern. Also, as Fig. 6 shows the higher wind speeds for both areas blow from northern directions, as expected. For the maritime gap exit area the stronger wind flow was from north-northwestern to east-northeastern direction with the mean wind speed exceeding $7 \mathrm{~m} \mathrm{~s}^{-1}$ in contrary to the maritime gap entrance area, where the mean maximum wind speed almost reached the value of $7 \mathrm{~m} \mathrm{~s}^{-1}$ (Fig. 6).

\section{Case study}

During the analyzed period three cases (15 July, 24 August and 16 September 2007) with sustained mean wind speed of the order of $14-15 \mathrm{~m} \mathrm{~s}^{-1}$ were reported at KS. In the present study the 24 August 2007 case was selected in order to study with more details the interaction of the northern flow over the Aegean with the complex topography of Crete. The choice of this Etesian wind event was based on the fact that this was the most severe episode during summer 2007 with wind 
gusts exceeding $24 \mathrm{~m} \mathrm{~s}^{-1}$ as well as that this episode persisted for more than three days, from 23 to 26 August 2007. During this period extensive forest fires were reported over the southern continental Greece resulted in the destruction of 1500 houses and the death up to 60 people.

\subsection{Synoptic description}

The synoptic description of the 24 August 2007 strong Etesian flow event over the Aegean was based on the use of analyses fields at 0.5 degrees resolution provided by the European Centre for Medium Range Weather Forecasts (ECMWF). At 12:00 UTC 23 August 2007 (the first day of the strong Etesian flow over the Aegean), a $500 \mathrm{hPa}$ trough was located at eastern Turkey, while a narrow tilted eastward upper level ridge developed over Ionian Sea and the Balkans (not shown). Meanwhile, at the surface a low pressure system was evident over southern Turkey with a low center of $1006 \mathrm{hPa}$. This low pressure system, often called the Turkish thermal low, is considered a western extension of the Asian thermal low (Meteorological Office, 1962). This synoptic combination favors the formation of an east-west pressure gradient over the Aegean.

At 06:00 UTC 24 August 2007, when the maximum winds were observed in $\mathrm{KS}$, the centre of the low pressure was located over the Cyprus $(\sim 1006 \mathrm{hPa})$, while high pressures over continental Greece were amplified at $1016-1020 \mathrm{hPa}$ (Fig. 7). The east-west pressure gradient over the Aegean was intensified to $\sim 6 \mathrm{hPa}$ over a distance of $\sim 300 \mathrm{~km}$ from the eastern coasts of continental Greece to west-southwestern Turkish coasts. Also, at the $500 \mathrm{hPa}$ level the geopotential pattern depicts a more extensive closed narrow ridge over the Balkans while the trough was more evident at the right part of Fig. 7. At 12:00 UTC 26 August 2007 an upper level trough was evident over the Balkans, while the ridge has been established over the Ionian Sea. This synoptic configuration is a feature of the beginning of the decay of the Etesian flow (Kotroni et al., 2001; Brody and Nestor, 1985). Additionally, the high pressure system over continental Greece has slightly diminished.

\subsection{Observations}

\subsubsection{Observations of general Etesian flow}

The general flow upstream as well as downstream of the island of Crete is examined from the QuikSCAT data at a spatial resolution of $12.5 \mathrm{~km} \times 12.5 \mathrm{~km}$. Figure 8 illustrates the $10 \mathrm{~m}$ wind fields at 04:20 UTC 24 August 2007 - closer to the time of the observed maximum wind at KS ( 06:00 UTC) - over the southern Aegean Sea. The island of Crete plays an important role in the modification of the wind flow. Upstream of the island the flow is clearly decelerated where the wind speed is diminished by at least $5 \mathrm{~m} \mathrm{~s}^{-1}$ in relation to

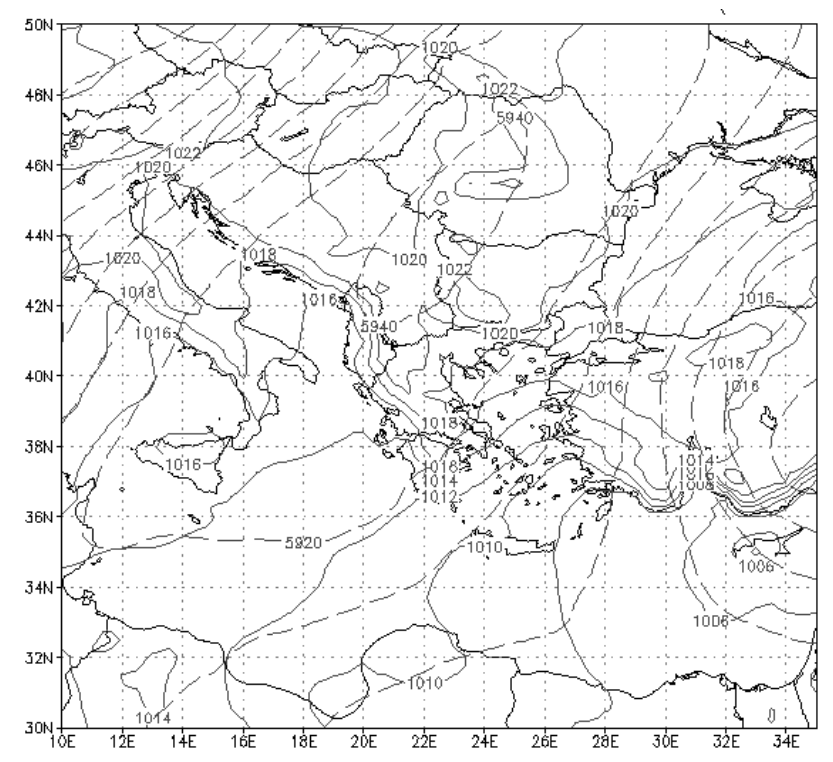

Fig. 7. ECMWF analyses of mean sea level pressure (solid lines at $2 \mathrm{hPa}$ interval) and $500 \mathrm{hPa}$ geopotential height (dashed lines at $20 \mathrm{~m}$ interval) at 06:00 UTC 24 August 2007.

the undisturbed flow. The decelerated area extended at a distance of about $110 \mathrm{~km}$ north of the island. This feature is more evident upstream of the western part, where the highest mountains are located (Fig. 1b) than in the eastern part. The decreased wind speed is also reported by the northern ground station of the experiment (RS) where only $7 \mathrm{~m} \mathrm{~s}^{-1}$ maximum mean wind speed was recorded during that day. One of the major observational characteristic is the clear leftward deflection of the wind field. The wind flow presents a north-northeasterly direction over the central Aegean turning northwesterly over the southeastern Aegean, which is a standard behavior of the Etesian flow (Kotroni et al., 2001).

In the area of southern Aegean, the maximum wind flow intensity is observed over the eastern and western edges of the island. Indeed, the flow acceleration at the maritime area east of the island has been attributed by Brody and Nestor (1985) to the channeling of the flow between Crete and the islands of Karpathos and Rhodos, but numerical sensitivity tests by Kotroni et al. (2001) revealed that this intensification of the wind flow is mainly related to the interaction of the flow with the complex terrain of the island. On the southern side of the island the flow was weaker, while weak mountain wakes were observed downstream of the highest mountains. Moreover, in contrary to Kotroni et al. (2001) $25 \mathrm{~km}$ ERS-2 scatterometer observations, restricted areas of increased wind speed on the lee side of the island were observed. These areas were related with the strong winds at the exits of mountain gaps. In Fig. 8 a local increase of the wind flow just downstream of the two highest mountains among the wakes is observed, while downstream of these areas a gradual decrease of wind speed occurred. 


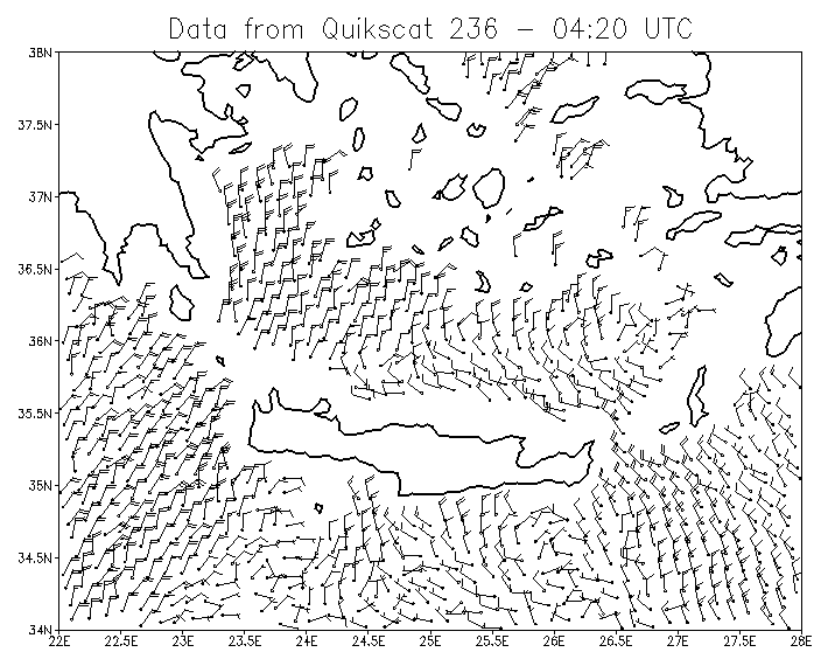

Fig. 8. QuikSCAT satellite wind fields valid at 04:20 UTC $24 \mathrm{Au}-$ gust 2007 over southern Aegean Sea. A full barb corresponds to $5 \mathrm{~m} \mathrm{~s}^{-1}$.

In order to investigate the vertical upstream structure of the Etesian flow, the soundings from Heraclion Airport (LGIR, WMO-16754) were examined. Heraclion Airport is located $65 \mathrm{~km}$ eastward of RS (Fig. 1b), but its location provides a good indicator of the upstream flow impinging on the island. The sounding at 12:00 UTC 24 August 2007 revealed two more stable layers in the lower atmosphere with a slight temperature inversion located at $900 \mathrm{hPa}$ up to $850 \mathrm{hPa}$ (a marine inversion due to advection of maritime air over the windward sides of the mountain), as well as a shallower temperature inversion at $750 \mathrm{hPa}$ (not shown). The deeper stable layer which is located at $900 \mathrm{hPa}$ was placed below the summit level of mountain Idi (Fig. 1b), which rises approximately at $750 \mathrm{hPa}$. This pattern resembles with the anticyclonic föhn, where a relatively cool air is dammed up on the windward side due to an anticyclonic inversion according to Cadez's classification of föhn winds (Cadez, 1967). One day later, by 12:00 UTC 25 August 2007 the temperature inversion is much shallower while at 12:00 UTC 26 August when the strong Etesian event decayed, the main characteristic of the vertical structure was the absence of stable layers in the whole atmosphere.

\subsubsection{Gap flow observations}

The wind speed time series during the strong Etesian flow event of 24 August 2007 is depicted by Fig. 9a. During the event, northerly winds gusting to $25 \mathrm{~m} \mathrm{~s}^{-1}$ occurred over the exit of the gap at KS. The strongest winds occurred during the daytime, with the maximum intensity observed at the southern exit of the gap (KS) while decreasing progressively towards the northern station (RS). As illustrated by the wind observations from KS, strong winds began at approximately
00:00 LST 23 August 2007 and present a peak of the wind speed at 09:00 LST on 24 August 2007. The mean wind speed remained above $10 \mathrm{~m} \mathrm{~s}^{-1}$ for approximately $17 \mathrm{~h}$ at KS and a cessation of the event was observed during nighttime of 25 August 2007. Throughout the event the wind speeds at RS as well as at AS did not exceed $8 \mathrm{~m} \mathrm{~s}^{-1}$. The wind speed time series presents a daily variation with the maximum values occurring in the morning and at noon for KS and MS respectively. The near calm wind speeds on AS during nighttime are remarkable, as it presents the lower gap flow intensity. This feature was also observed during the entire period of the experiment, as depicted in Fig. 2c, d.

The wind observation of the gap flow indicates that the strongest winds are located in the exit area of the gap (KS). Therefore, the primary cause of the strong winds is not the Venturi effect. However, at the second day of the event (25 August 2007) strong winds are observed at the MS, also. Perhaps this wind maximum in the gap might occur due to local topography, Venturi and/or other hydraulic effects (Jackson and Steyn, 1994; Sharp and Mass, 2002). For such an analysis, three dimensional fields are needed that could be provided by high resolution numerical simulations, but this is beyond the scope of this paper.

Figure $9 \mathrm{~b}$ presents the temperature distribution for all gap stations. The temperature time series for each station follows the diurnal heating cycle with the maximum values throughout the day (24-h) observed at KS. The daily temperature maxima of RS, MS and AS are $4-5^{\circ} \mathrm{C}$ lower than at $\mathrm{KS}$ (Fig. 9b). Relatively cool air can form in place at the inland stations (AS, MS) due to radiational cooling and katabatic winds from the adjacent mountains resulting in the temperature minima which are remarkable lower at the inland stations during nighttime. Analysis of temperature at 2 and $5 \mathrm{~m}$ showed that the inland AS experiences more radiational cooling due to light winds as shown in Fig. 2d, than in MS. The maritime influence of the RS in the entrance of the gap is also evident through the lower difference between daily minimum and maximum temperature (Fig. 9b). Additionally, the temperature as well as the humidity field of KS is strongly affected by the descending warmer air from the adjacent mountains. The temperature contrast between the entrance and the exit of the gap can be attributed to a temperature gradient during an Etesian flow. Such a thermal gradient can enhance a low-level pressure gradient across a gap that can contribute to the intensification of the flow (Sharp and Mass, 2004).

The mean sea level pressure (mslp) time variation down the gap was examined using the 5-min observational data from 00:00 LST 23 August 2007 to 00:00 LST $26 \mathrm{Au}$ gust 2007 (not shown). Throughout the experiment period (July to September 2007) the sea level pressure in gap entrance (RS) was higher than exit (KS) causing a mean pressure difference $2.6 \mathrm{hPa}$. However, when a northerly wind regime is established over the Aegean Sea (time period of NWFD), the mean pressure difference is increased to $3.2 \mathrm{hPa}$. The time variation of mean sea level pressure for all gap 


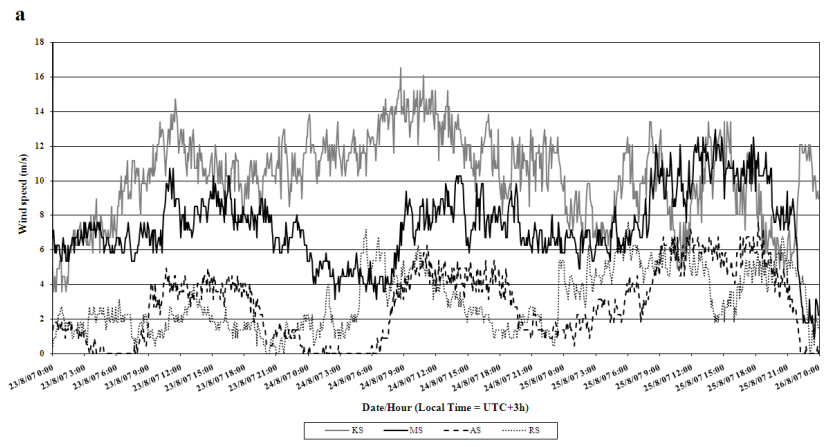

b

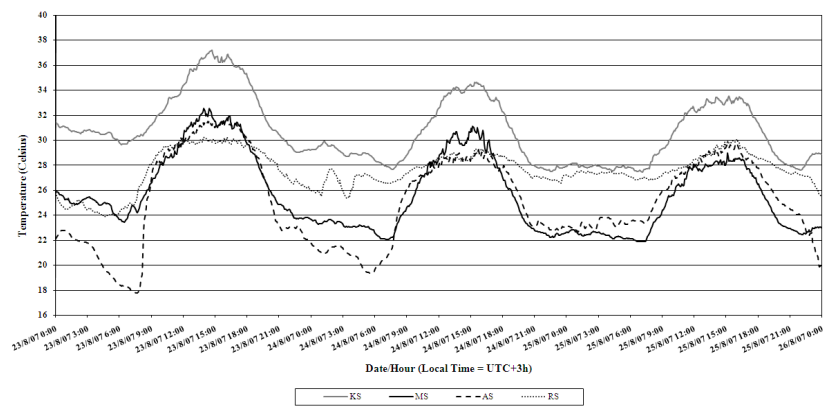

Fig. 9a, b. Time series of 5-min mean (a) wind speed $\left(\mathrm{m} \mathrm{s}^{-1}\right)$ at $10 \mathrm{~m}$, (b) temperature (Celsius) at $2 \mathrm{~m}$ from the ground stations at Kerame (KS), Mourne (MS), Armeni (AS) and Rethymno (RS) for 23-26 August 2007.

stations presents the same time evolution, but the major characteristic of the mslp time series is the persistent lower pressure at KS, which was evident throughout the Etesian event. The high mountains in which the gap is embedded block the relatively cool maritime air on the windward side producing higher pressures at low level. According to the soundings information the windward air was shallow capped by a marine temperature inversion below the crest level of the mountains, so that air could escape through the gap and finally arrived at the gap exit (KS), where the gap widens rapidly. Since the surface pressure depends on the depth of the relatively cool dense air, the rapid thinning of the cooler air layer results in a large drop of pressure. Since this shallowing of cool, dense air is similar to the shallowing of a layer of water as it passes out of a reservoir, the developing gradient is called hydraulic pressure gradient. In turn, this pressure gradient contributes to an acceleration of the low-level gap flow over the exit region.

The relation of the pressure gradient between the entrance (RS) and the exit (KS) of the gap with the wind speed at the exit of the gap is illustrated in Fig. 9c. Between 00:00 LST and 11:30LST 23 August 2007 the winds at KS increase gradually from $\sim 4$ to $15 \mathrm{~m} \mathrm{~s}^{-1}$, while the pressure difference rose from 2.6 to $4.7 \mathrm{hPa}$. The variation of the pressure difference was in phase with the changes in KS wind speed. For example the increase in pressure difference from

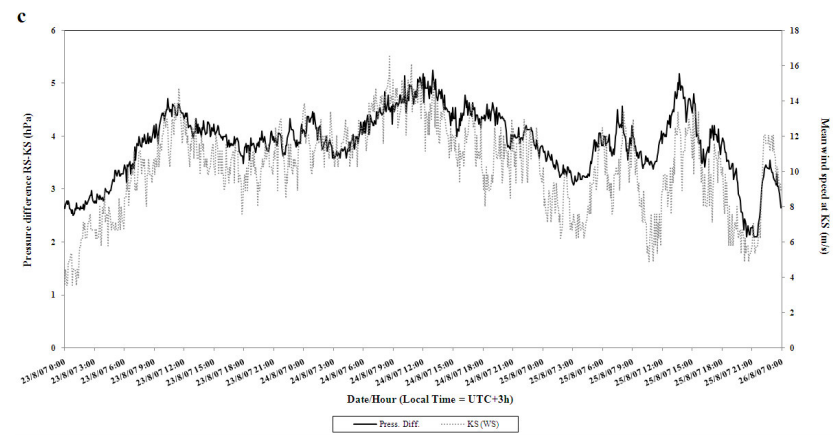

Fig. 9c. Time series of 5-min mean (c) sea level pressure difference between the (RS) and (KS) as well as the wind speed at (KS) for 23-26 August 2007.

3.6 (04:20 LST 24 August) to $5.3 \mathrm{hPa}$ (13:00 LST 24 August) matched up with an increase in KS wind speed from 11.6 to $14.3 \mathrm{~m} \mathrm{~s}^{-1}$. Also, the rapid decrease in pressure difference from 4.2 (17:15 LST 25 August) to $2 \mathrm{hPa}$ (20:45 LST $25 \mathrm{Au}$ gust) was in agreement with the wind speed decrease in KS from 11.6 to $5.4 \mathrm{~m} \mathrm{~s}^{-1}$.

\section{Conclusions}

This study has examined the interaction of the northern wind flow over the Aegean Sea with the complex topography of Crete Island, and particular the significance of the gap flow between the two highest Cretan mountains Lefka Ori and Idi. To achieve this objective a network of surface observations data collected during summer 2007 have been analyzed, along with QuikSCAT high resolution satellite wind data.

From the 92 days of the experiment during summer of 2007, 48-days were characterized as northern wind flow days (NWFD). The statistical analysis of the wind speed and direction revealed that the prevailing wind direction during NWFD for all gap locations is the northern. The small differences in the wind direction are related with the local topographic elements. Moreover, near gale winds (exceeding $15 \mathrm{~m} \mathrm{~s}^{-1}$ ) occur at and near the gap exit stations (KS, MS) and decrease gradually to the northern stations (AS, RS). At RS (the most northern station) a significant percentage of light south winds during nighttime and early morning hours have been observed in contrary to the maritime area upstream of the gap entrance. The existence of this reverse wind flow implies the presence of a land breeze, which is evident at the entrance of the gap due to the decelerated northern flow caused by the blocked upstream flow. The hourly distribution of wind speed shows that during daytime the inland stations (AS, MS) present the higher wind speed variability contrary to the coastal stations (RS, KS). The mean gust factor at KS varies from 1.4 to 1.8 . The surrounding topography at KS seems to affect the gust intensity. As it was mentioned before, the stronger winds are observed at the gap exit region 
contrary to the Venturi effect, implying that the main cause of the strong winds is the pressure different between the gap entrance and exit.

For that reason the pressure difference between the entrance of the gap (RS) and the exit (KS) was analyzed. During the northerly flow over the Aegean, a significant pressure difference between RS and KS was evident. The high value of the coefficient of determination $\left(R^{2}=0.70\right)$ of the pressure difference with the northerly wind speeds at KS denotes that the pressure gradient between the entrance and exit of the gap is an adequate indicator for the gap exit wind speed.

Further, it was found that the northerly winds at KS are accompanied with an increase in mean maximum temperatures with a simultaneous decrease of the relative humidity. These conditions are related to the adiabatic warming of the mountainous gap environment. On the contrary, the southern winds bring maritime air at the KS resulting in the decrease of the maximum temperatures and a simultaneous increase of the relative humidity.

In addition, a case study of strong gap flow event that occurred in 24 August 2007 has also been performed. The synoptic pattern favored the development of an Etesian wind flow. The observational analysis of the QuikSCAT's data revealed the formation of a deceleration area upstream of Crete with near calm wind conditions at the northern side as well as the deflection of the wind flow around the island. Downstream of the island, formations of mountain wakes as well as areas with localized maximum wind speeds were observed. The localized intensification of the flow downstream is related to the channeling of the flow through the gaps. During the event, relative cooler maritime air approached the island and dammed up the high mountains. The thermal gradient between the gap entrance and the exit, which is evident throughout the event, may have amplified the pressure gradient along the gap. The pressure difference RS and KS was strongly correlated with the wind speed at KS, while the wind speed and pressure difference changes were in phase.

This work aimed to contribute to the understanding of the interaction of the flow with the complex topography of Crete Island under a northerly wind regime over the Aegean Sea. This study was based on the available observations. In order to further analyze this interaction, fine resolutions mesoscale model simulations are needed. It is in the authors plan to use a non-hydrostatic high resolution mesoscale model to perform simulation with a grid increment of $\sim 1 \mathrm{~km}$ in order to further study the characteristics of the gap flow, the changes in the vertical atmospheric structure, the development of mountain wakes as well as the changes on temperature fields especially downstream of the island.
Acknowledgements. ECMWF is kindly acknowledged for the provision of gridded analyses data. The satellite data have been downloaded from the web site http://podaac.jpl.nasa.gov/. The authors are grateful to Spyridon Lykoudis (National Observatory of Athens, Greece) for his valuable comments on the paper. Also, thanks are given to Nikolaos Mazarakis (National Observatory of Athens, Greece) and to Dimitrios Katsanos (National Observatory of Athens, Greece) for their valuable contribution to the experiment. Special thanks to the Municipality of Rethymno for its help and collaboration.

Edited by: S. Michaelides, K. Savvidou, and F. Tymvios Reviewed by: M. Hatzaki and another anonymous referee

\section{References}

Bitan, A. and Saaroni, H.: The horizontal and vertical extension of the Persian Gulf trough, Int. J. Climatol. 12, 733-747, 1992.

Brennan, J. M., Cobb, H. D., and Knabb, R. D.: Observations of Gulf of Tehuantepec gap wind events from QuikSCAT: An updated event climatology and operational model evaluation, 22nd Conference on weather analysis and forecasting/18th conference on numerical weather prediction, 8A4, 2007.

Brody, L. R. and Nestor, M. J. R.: Regional forecasts for the Mediterranean basin, Technical Report, No. 80-110, Naval Environmental Prediction Research Facility, Monterey, California, USA, 1985.

Cadez, M.: Uber synoptische Probleme in Südostalpinen Raum, Veröff. Schweiz. Met. Zentralanstalt, 4, 155-175, 1967.

Colle, B. A. and Mass, C. F.: High-resolution observations and numerical simulations of easterly gap flow through the strait of Juan de Fuca on 9-10 December 1995, Mon. Wea. Rev., 128, 23982422, 2000.

Devore, J. L.: Probability and Statistics for Engineering and the Sciences, Third Edition, Brooks/Cole Publishing Company, 492 pp., 1991.

Durran, D. R.: Mountain waves and downslope winds, in: Atmospheric Processes over Complex Terrain, edited by: Blumen, W., Amer. Meteor. Soc., 59-81, 1990.

Jackson, P. L. and Steyn, D. G.: Gap winds in a Fjord. Part I: Observations and numerical simulation, Mon. Wea. Rev., 122, 26452665, 1994.

Kotroni, V., Lagouvardos K., and Lalas, D.: The effect of the island of Crete on the Etesian winds over the Aegean Sea, Q. J. R. Meteorol. Soc., 127, 1917-1937, 2001.

Lungu, T. and Coauthors: QuikSCAT science data product user's manual version 3.0, Jet Propulsion Laboratory Rep, D-18053Rev A, 97 pp., 2006.

Metaxas, D. and Bartzokas, A.: Pressure covariability over the Atlantic, Europe and N. Africa. Application: centers of action for temperature, winter precipitation and summer winds in Athens, Greece, Theor. Appl. Climatol., 49, 9-18, 1994.

Metaxas, D.: The interannual variability of the Etesian frequency as a response of atmospheric circulation anomalies, Bull. Hell. Meteorol. Soc., 2, 30-40, 1977.

Meteorological Office: Weather in Mediterranean, Vol. I, General Meteorology, H.M.S.O., London, Second Edition, 1962.

Overland, J. E. and Walter Jr, B. A..: Gap winds in the Strait of Juan de Fuca, Mon. Wea. Rev., 109, 2221-2233, 1981. 
Overland, J. E.: Scale analysis of marine winds in straits and along mountainous coasts, Mon. Wea. Rev., 112, 2530-2534, 1984.

Pan, F. and Smith, R. B.: Gap winds and wakes: SAR observations and numerical simulations, J. Atmos. Sci., 56, 905-922, 1999.

Prezerakos, N.: Linear correlation of north component winds greater than Beaufort force 5 and the pressure gradient between Thessaloniki and Rhodos, Meteorologica, No. 51, Publication of the Meteorological Institute of the University of Thessaloniki, 1975.

Reed, T. R.: Gap winds in the Strait of Juan de Fuca, Mon. Wea. Rev., 59, 373-376, 1931.
Sharp, J. and Mass, C. F.: Columbia Gorge gap flow - Insights from observational analysis and ultra-high-resolution simulation, Bull. Amer. Meteor. Soc., 83, 1757-1762, 2002.

Sharp, J. and Mass, C. F.: Columbia gorge winds: their climatological influence and synoptic evolution, Wea. Forecast., 19, 970992, 2004.

Smith, R. B., Gleason, A. C., Gluhosky, P. A., and Grubisic, V.: The wake of St. Vincent, J. Atmos. Sci., 54, 606-623, 1997.

Ziv, B., Saaroni H., and Alpert, P.: The factors governing the summer regime of the eastern Mediterranean, Int. J. Climatol., 24, 14, 1859-1871, 2004. 